OPEN ACCESS

Edited by:

Zhao Wang

University of Electronic Science and

Technology of China, China

Reviewed by:

Ruizheng Shi,

Central South University, China

Jinwei Tian,

The Second Affiliated Hospital of

Harbin Medical University, China

*Correspondence:

Song Ding

dingsong1105@163.com

Jun Pu

pujun310@hotmail.com

tThese authors have contributed equally to this work

Specialty section: This article was submitted to Cardiovascular Imaging a section of the journal Frontiers in Cardiovascular Medicine

Received: 31 March 2021 Accepted: 04 June 2021

Published: 22 July 2021

Citation:

Luo G, Qian Y, Sheng X, Sun J, Wu Z, Liao F, Feng $Q$, Yin $Y$, Ding $S$ and $P u J$ (2021) Elevated Serum Levels of Soluble ST2 Are Associated With Plaque Vulnerability in Patients With Non-ST-Elevation Acute Coronary Syndrome.

Front. Cardiovasc. Med. 8:688522. doi: 10.3389/fcvm.2021.688522

\section{Elevated Serum Levels of Soluble ST2 Are Associated With Plaque Vulnerability in Patients With Non-ST-Elevation Acute Coronary Syndrome}

\author{
Guqing Luo ${ }^{1 \dagger}$, Yuxuan Qian ${ }^{1 \dagger}$, Xincheng Sheng ${ }^{1}$, Jiateng Sun ${ }^{1}$, Zhinan Wu ${ }^{1}$, Fei Liao ${ }^{1}$, \\ Qi Feng ${ }^{2}$, Yan Yin ${ }^{2}$, Song Ding ${ }^{1 *}$ and Jun $\mathrm{Pu}^{1 *}$ \\ ${ }^{1}$ Department of Cardiology, School of Medicine, Renji Hospital, Shanghai Jiaotong University, Shanghai, China, ${ }^{2}$ Department \\ of Radiology, School of Medicine, Renji Hospital, Shanghai Jiaotong University, Shanghai, China
}

Background: Recent studies have suggested that soluble suppression of tumorigenicity-2 (SST2), an inflammation-related protein receptor, is associated with atherosclerotic diseases. This study aimed to investigate the potential predictive value of SST2 on plaque vulnerability by assessing whether elevated serum levels of sST2 are associated with vulnerable plaque features in patients with non-ST-elevation acute coronary syndrome (ACS).

Methods: A total of 120 patients with non-ST-elevation ACS (167 lesions) were prospectively enrolled and evaluated by standard coronary computed tomography angiography (CCTA) and coronary angiography in this study. Serum sST2 levels were measured by ELISA (Presage ${ }^{\circledR}$ ST2 Assay Kit, Critical Diagnostics), and semiautomated software (QAngioCT, Medis) was used to quantify coronary plaques.

Results: The included patients were divided into 4 groups by serum SST2 level quartiles. Volumetric analysis of the whole lesion revealed that patients with higher sST2 levels had a larger absolute necrotic core (NC) volume (Quartile 4 vs. Quartile 1, $86.16 \pm 59.71$ vs. $45.10 \pm 45.80 \mathrm{~mm}^{3}, P=0.001$; Quartile 4 vs. Quartile 2, $86.16 \pm 59.71$ vs. $50.22 \pm$ $42.56 \mathrm{~mm}^{3}, P=0.002$ ) and a higher NC percentage (Quartile 4 vs. Quartile 1, $35.16 \pm$ 9.82 vs. $23.21 \pm 16.18 \%, P<0.001$; Quartile 4 vs. Quartile $2,35.16 \pm 9.82 \%$ vs. 22.50 $\pm 14.03 \%, P<0.001$; Quartile 4 vs. Quartile 3, $35.16 \pm 9.82 \%$ vs. $25.04 \pm 14.48 \%, P$ $<0.001)$. Correlation analysis revealed that serum sST2 levels were positively correlated with the NC $(r=0.323, P<0.001)$ but negatively correlated with dense calcium $(r=$ $-0.208, P=0.007$ ). Furthermore, among those with plaque calcification, patients with spotty calcification exhibited higher serum sST2 levels than those with large calcification (26.06 \pm 16.54 vs. $17.55 \pm 7.65 \mathrm{ng} / \mathrm{mL}, P=0.002$ ). No significant differences in plaque components at the level of the minimal lumen area (MLA) were found among the groups. 


\begin{abstract}
Conclusions: Serum SST2 levels were correlated with different coronary plaque components in patients with non-ST-elevation ACS. A higher serum level of sST2 was correlated with plaque vulnerability.
\end{abstract}

Clinical Trial Registration: www.ClinicalTrials.gov, identifier: NCT04797819.

Keywords: coronary computed tomography angiography, coronary plaque, plaque vulnerability, soluble ST2, non-ST elevation acute coronary syndromes

\section{INTRODUCTION}

Rupture of vulnerable plaques and subsequent thrombosis are the main triggers of acute coronary syndrome (ACS), and researchers are becoming increasingly interested in the early identification of vulnerable plaques. Standard intracoronary imaging methods, such as intravascular ultrasound (IVUS) and optical coherence tomography (OCT), are used to quantify the distribution and severity of coronary plaques but are limited by their invasive features. Coronary computed tomographic angiography (CTA) is a sensitive and non-invasive modality widely used for the diagnosis of coronary artery disease. QAngioCT can quantitatively analyze stenosis, plaque burden, and specific intraplaque components of coronary CTA (CCTA) images by obtaining 3-dimensional centerline of coronary artery and reconstructing coronary artery volume via a fast vessel-tracking algorithm $(1,2)$. Furthermore, several studies supported the feasibility of non-invasive quantitative CCTA (QCCTA) via QAngioCT software to assess plaque burden and plaque components when compared to quantitative coronary angiography (QCA) or virtual histology (VH)-IVUS analysis (1-3).

Inflammation plays an essential role in the pathogenesis of plaque vulnerability (4). sST2, a soluble form of ST2, can modulate the inflammatory response and exert proinflammatory effects when secreted into the circulation $(4,5)$. Elevated serum levels of sST2 have been observed in patients with several inflammatory and autoimmune diseases, including inflammatory bowel disease, asthma, and rheumatoid arthritis. Several studies have focused on the association between serum sST2 and cardiovascular diseases. Previous studies demonstrated that elevation of serum sST2 levels was associated with poor prognosis in patients with myocardial infarction (MI) or heart failure (HF) (6-8). An animal study has reported that administration of sST2 exacerbated atherosclerosis development in a mouse model (9). Consistent with that, a recent study by Zhang et al. showed that serum sST2 levels were elevated in patients with ACS, especially in those with complex lesions (4). In this study, we aimed to investigate the relationships between serum sST2 levels and CCTA-based plaque components in patients with non-ST-elevation ACS. We hypothesized that elevated serum sST2 level might be closely related to vulnerable plaque features, serving as a reliable sensor of coronary immuneinflammatory disorder and a simple indicator for coronary plaque vulnerability.

\section{METHODS}

\section{Study Population}

Patients with non-ST-elevation ACS who required an immediate $(<2 \mathrm{~h})$ or early invasive strategy $(<24 \mathrm{~h})$ according to guidelines, including those who presented with hemodynamic instability or cardiogenic shock, life-threatening arrhythmias or cardiac arrest, mechanical complications, acute heart failure, dynamic ST or T wave changes, or a Global Registry of Acute Coronary Events (GRACE) score $>140$, were excluded (10). In addition, subjects with a previous history of coronary artery bypass graft surgery or percutaneous coronary intervention (PCI), immune system disorder, cancer, acute/chronic infection, statin use within 3 months, atrial fibrillation, end-stage renal failure, or iodine-containing contrast allergy were excluded. Between January 2019 and December 2019, a total of 159 patients with non-ST-elevation ACS (non-ST-elevation myocardial infarction or unstable angina) aged 18-75 years who underwent CCTA were prospectively enrolled in this study. After CCTA, we also excluded patients with no significant $(\geq 50 \%)$ stenosis of major epicardial vessels $(n=26)$ and those who refused subsequent angiography $(n=3)$. Among the 130 remaining patients who received angiography, those with total obstruction of major epicardial vessels $(n=4)$ or insufficient image quality for QAngioCT analysis $(n=6)$ were excluded. Finally, a total of 120 patients with 167 lesions were included in our study for the final analysis (Figure 1). The baseline features and cardiovascular risk factors of the study subjects were documented. This study was approved by the Institutional Review Board of Renji Hospital, and all subjects provided written informed consent.

\section{Serum sST2 and Other Biochemical Indicators Measurement}

At admission, four milliliters of venous blood were collected from the antecubital veins of patients hospitalized for the angiography procedure into EDTA-containing tubes. The blood was centrifuged at $3,000 \mathrm{~g}$ for $5 \mathrm{~min}$ within $1 \mathrm{~h}$ of collection, and the serum was immediately separated and stored at $-80^{\circ} \mathrm{C}$ for further testing. Serum sST2 levels were measured with a commercial ELISA kit (Presage ${ }^{\circledR}$ ST2 Assay Kit, REF\#BC1065, Critical Diagnostics, San Diego, CA) according to the manufacturer's instructions. Following standard laboratory techniques, other serum biochemical indicators including alanine transaminase (ALT), serum creatinine (Scr), high-sensitivity 


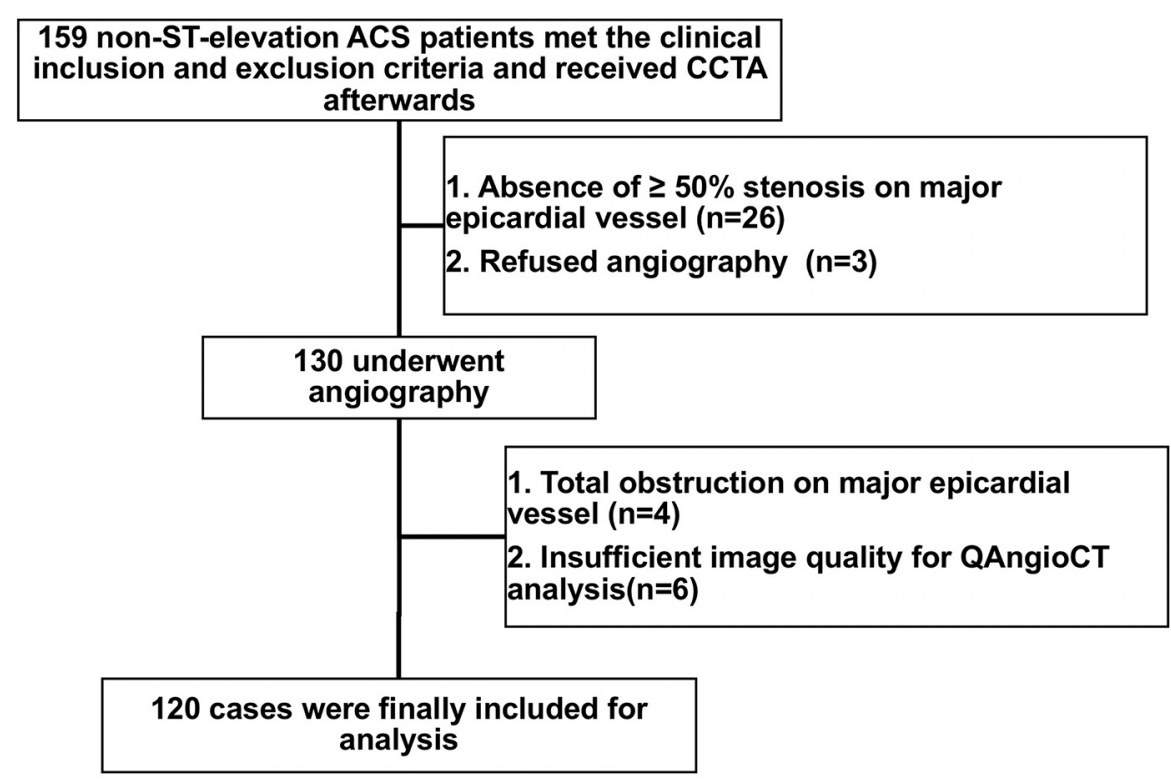

FIGURE 1 | Flowchart of patient enrollment. ACS, acute coronary syndrome; CCTA, coronary computed tomography angiography.

C-reactive protein (hs-CRP), and low-density lipoprotein (LDL) were analyzed at hospital admission as well.

\section{Enhanced Coronary CTA}

Enhanced coronary CT scans were obtained from all of the included patients on a 320-slice CT scanner (Aquilion ONE, Toshiba Medical Systems, Otawara, Japan). To optimize the imaging quality, oral metoprolol was administered to patients with a heart rate $>75$ beats $/$ min prior to the CT scan. The tube voltage and current for each patient was determined by Toshiba integrated dose reduction technique (SureExposure 3D). Electrocardiograms were used for retrospective gating to eliminate motion interference. Imaging data were reconstructed at a slice thickness of $0.5 \mathrm{~mm}$ and a reconstruction interval of $0.25 \mathrm{~mm}$. All the results were interpreted by radiologists with board certifications for cardiac CT interpretation.

\section{Plaque Characteristics Analysis}

CCTA data were transferred to offline workstations. Plaque characteristics were semiautomatically analyzed using QAngioCT software (Medis ${ }^{\circledR}$ QAngio CT V3.1, Medis Medical Imaging Systems, Leiden, the Netherlands). All lesions with a stenosis of $\geq 50 \%$ underwent quantitative analysis (11-13). Plaque characteristics were analyzed by two trained observers who were blinded to the clinical characteristics of the corresponding patients. QAngioCT software was used for the automated 3-dimensional reconstruction of the coronary artery volume to determine the contours of the vessel wall and lumen (Figure 2). Volumetric characterization of the plaque characteristics focused on the entire plaque volume under 3-dimensional reconstruction, while the cross-sectional characterization focused at the level of the minimal lumen area
(MLA) $(2,14)$. And in our study, the level of the MLA was automatically identified using the lumen contours detected on coronary CTA (2). Different plaque components on CCTA were distinguished by Hounsfield unit (HU) values, and different cut-off values were available in previous studies, which were obtained by comparing coronary CTA with VH-IVUS or histological examination $(15,16)$. For the current study, a density of $-30 \sim 75$ HUs indicated necrotic core (NC), while a density of $76 \sim 130$ HUs indicated fibrous fatty (FF), a density of 131 $\sim 350$ HUs indicated fibrous tissue (FT), and a density $>351$ HUs indicated dense calcium (DC) $(14,17)$. The eccentricity index and remodeling index were automatically calculated by QAngioCT software. Eccentricity index was calculated as (maximal plaque thickness minus minimal plaque thickness) divided by maximal plaque thickness $(2,18,19)$. At the level of the minimal lumen area, the remodeling index was calculated by dividing the cross-sectional vessel wall area by the corresponding reference area. The cross-sectional reference area was determined in the normal-appearing reference area as close as possible to the respective coronary lesion $(2,18,20)$. Spotty calcification was defined when $<3 \mathrm{~mm}$ in size on curved multiplanar reformation images and 1-sided on cross-sectional images. Large calcification was defined as the calcification larger than spotty calcification $(21,22)$.

\section{Statistical Analysis}

Statistical analyses were performed using IBM SPSS Statistics 23 (SPSS, Inc., Chicago, IL). Summary statistics of continuous data with symmetric distribution are expressed as the mean \pm standard deviation (SD), while categorical data are expressed as counts (percentages). Comparison of continuous variables between two groups was performed using the independent 


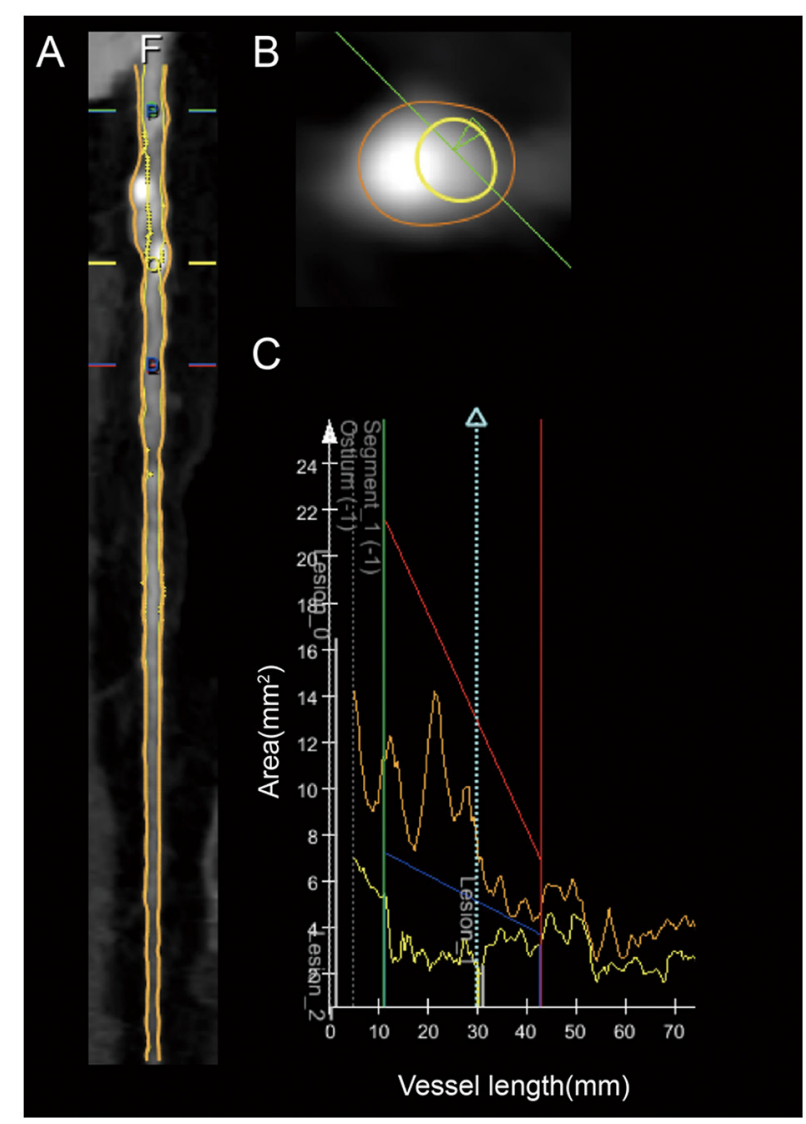

FIGURE 2 | Example of the coronary plaque quantitative analysis of a lesion in the proximal $L A D$ artery segment. (A) Longitudinal straightened multiplanar reconstruction, where "O" indicates the minimal lumen area. (B)

Cross-sectional view of minimal lumen area. (C) Graph of the lumen and vessel area as a function of vessel length.

sample $t$-test, while categorical variables were compared using the chi-squared test. Pearson's chi-square test was used to compare the constituent ratios and to assess the correlations between two continuous variables. $P<0.05$ indicate statistical differences. Furthermore, threshold level of significance for differences among groups were adjusted for multiple comparisons by Bonferroni's correction. As 6 tests were performed among 4 groups, the differences were statistically significant when the observed $P$-values were less than the specified significance level $(\alpha)$ divided by the number of tests $(K)$ $=0.05 / 6<0.0084$.

\section{RESULTS}

\section{Baseline Characteristics}

Out of 120 patients, 167 lesions were analyzed in our study. Eighty-two patients had one lesion undergoing analysis, while 29 patients had two lesions and 9 patients had three lesions undergoing analysis. Patients were classified into 4 groups according to the serum sST2 level quartiles (sST2 $<14.5 \mathrm{ng} / \mathrm{mL}$,
Quartile 1; $14.5 \mathrm{ng} / \mathrm{mL} \leq \mathrm{sST} 2<20.5 \mathrm{ng} / \mathrm{mL}$, Quartile 2; $20.5 \mathrm{ng} / \mathrm{mL} \leq \mathrm{sST} 2<25.9 \mathrm{ng} / \mathrm{mL}$, Quartile 3; sST2 $\geq 25.9 \mathrm{ng} / \mathrm{mL}$, Quartile 4). A comparison of the baseline characteristics is shown in Table 1. Patients with higher serum sST2 levels were older (Quartile 4 vs. Quartile 2, $70.27 \pm 8.38$ vs. $64.17 \pm 8.91 \mathrm{ng} / \mathrm{mL}, P$ $=0.008)$. There were no statistically significant differences in the sex, BMI, heart rate, blood pressure, incidence of hypertension, hyperlipemia, diabetes mellitus, chronic obstructive pulmonary disease, known valvular disease, ALT level, Scr level, hs-CRP level, or eGFR among the groups. The lesion distributions across the main coronary arteries were not significantly different.

\section{Serum sST2 Level and Plaque Components in Volumetric Analysis of the Whole Lesion}

As shown in Table 2, the relationships between the serum sST2 level and the absolute volumes or percentages of four different plaque components throughout the entire lesion were assessed. We found that patients with higher sST2 levels had a larger absolute NC volume (Quartile 4 vs. Quartile 1, 86.16 \pm 59.71 vs. $45.10 \pm 45.80 \mathrm{~mm}^{3}, P=0.001$; Quartile 4 vs. Quartile 2, 86.16 \pm 59.71 vs. $\left.50.22 \pm 42.56 \mathrm{~mm}^{3}, P=0.002\right)$ and a higher NC percentage (Quartile 4 vs. Quartile 1, $35.16 \pm 9.82 \%$ vs. $23.21 \pm$ $16.18 \%, P<0.001$; Quartile 4 vs. Quartile 2, $35.16 \pm 9.82 \%$ vs. $22.50 \pm 14.03 \%, P<0.001$; Quartile 4 vs. Quartile 3, $35.16 \pm$ $9.82 \%$ vs. $25.04 \pm 14.48 \%, P<0.001)$. On the contrary, patients with higher sST2 levels had a lower DC percentage (Quartile 4 vs. Quartile 1, $7.23 \pm 9.76 \%$ vs. $18.07 \pm 22.13 \%, P=0.005$; Quartile 4 vs. Quartile 2, $7.23 \pm 9.76 \%$ vs. $17.66 \pm 19.89 \%, P=0.003$ ). No differences were observed in the other plaque characteristics, including the mean plaque burden, maximal plaque thickness, FT and FF components. The serum sST2 level was positively correlated with both the absolute NC volume (Pearson's $r=$ 0.323, $P<0.001$ ) and the NC percentage (Pearson's $r=0.425, P$ $<0.001)$. In addition, the serum sST2 level was mildly negatively correlated with the absolute DC volume (Pearson's $r=-0.208$, $P=0.007$ ) and the DC percentage (Pearson's $r=-0.275, P<$ 0.001) (Table 3).

\section{Serum sST2 Level and Plaque Components at the Level of the Minimal Lumen Area (MLA)}

As shown in Table 4, there were no differences in the plaque components at the level of the minimal lumen area among the groups.

\section{Soluble ST2 and Plaque Calcification}

Different types of plaque calcification play different roles in plaque vulnerability. To further clarify the correlation between the serum sST2 level and coronary plaque calcification, we divided patients into two groups based on the existence of plaque calcification. The results showed no significant difference in the serum sST2 levels $(22.87 \pm 14.44$ vs. $24.47 \pm 15.63 \mathrm{ng} / \mathrm{mL}, P$ $=0.494)$ between the calcification and non-calcification groups (Figure 3A). However, further division of the calcification group into two subgroups by the plaque calcification type revealed that patients with spotty calcification had higher sST2 levels 
TABLE 1 | Baseline characteristics.

\begin{tabular}{|c|c|c|c|c|c|c|c|c|c|c|}
\hline & \multirow{2}{*}{$\begin{array}{c}\text { Quartile } 1 \\
(N=30) \\
<14.5 \mathrm{ng} / \mathrm{mL}\end{array}$} & \multirow{2}{*}{$\begin{array}{c}\text { Quartile } 2 \\
(N=30) \\
14.5-20.5 \\
n g / m L\end{array}$} & \multirow{2}{*}{$\begin{array}{c}\text { Quartile } 3 \\
(N=30) \\
20.5-25.9 \\
n g / m L\end{array}$} & \multirow{2}{*}{$\begin{array}{c}\text { Quartile } 4 \\
(N=30) \\
>25.9 \mathrm{ng} / \mathrm{mL}\end{array}$} & \multicolumn{6}{|c|}{$P$-value } \\
\hline & & & & & $\begin{array}{c}\text { Quartile 2 } \\
\text { vs. } \\
\text { Quartile 1 }\end{array}$ & $\begin{array}{c}\text { Quartile 3 } \\
\text { vs. } \\
\text { Quartile 1 }\end{array}$ & $\begin{array}{c}\text { Quartile } 4 \\
\text { vs. } \\
\text { Quartile 1 }\end{array}$ & $\begin{array}{c}\text { Quartile } 3 \\
\text { vs. } \\
\text { Quartile } 2\end{array}$ & $\begin{array}{c}\text { Quartile } 4 \\
\text { vs. } \\
\text { Quartile 2 }\end{array}$ & $\begin{array}{c}\text { Quartile } 4 \\
\text { vs. } \\
\text { Quartile 3 }\end{array}$ \\
\hline Age, yrs & $65.10 \pm 8.48$ & $64.17 \pm 8.91$ & $65.60 \pm 6.78$ & $70.27 \pm 8.38$ & 0.679 & 0.802 & 0.021 & 0.486 & 0.008 & 0.021 \\
\hline Sex, M/F & $20 / 10$ & $24 / 6$ & $21 / 9$ & $22 / 8$ & 0.250 & 0.786 & 0.581 & 0.380 & 0.549 & 0.779 \\
\hline SBP, mmHg & $136.17 \pm 14.34$ & $131.07 \pm 14.64$ & $135.87 \pm 20.92$ & $132.97 \pm 24.85$ & 0.178 & 0.949 & 0.544 & 0.308 & 0.720 & 0.627 \\
\hline HTN, $n(\%)$ & $20(66.7)$ & $23(76.7)$ & $20(66.7)$ & $17(56.7)$ & 0.399 & 1.000 & 0.434 & 0.399 & 0.104 & 0.434 \\
\hline DM, $n(\%)$ & 7 (23.3) & 10 (33.3) & $11(36.7)$ & $15(50.0)$ & 0.390 & 0.260 & 0.032 & 0.787 & 0.190 & 0.297 \\
\hline COPD, $n(\%)$ & $3(10.0)$ & 4 (13.3) & $3(10.0)$ & $5(16.7)$ & 0.688 & 1.000 & 0.448 & 0.688 & 0.718 & 0.448 \\
\hline $\begin{array}{l}\text { Known valvular } \\
\text { disease, } n(\%)\end{array}$ & 1 (3.3) & $1(3.3)$ & $0(0)$ & $2(6.7)$ & 1.000 & 0.313 & 0.554 & 0.313 & 0.554 & 0.150 \\
\hline $\begin{array}{l}\text { eGFR, } \\
\mathrm{mL} /\left(\mathrm{min}^{\star} \mathrm{l} .73\right. \\
\left.\mathrm{m}^{2}\right)\end{array}$ & $97.27 \pm 16.18$ & $101.63 \pm 28.27$ & $100.29 \pm 30.73$ & $94.37 \pm 18.12$ & 0.468 & 0.636 & 0.515 & 0.862 & 0.242 & 0.368 \\
\hline LDL, mmol/L & $2.49 \pm 0.69$ & $2.32 \pm 0.79$ & $2.59 \pm 0.83$ & $2.29 \pm 0.79$ & 0.391 & 0.615 & 0.321 & 0.212 & 0.898 & 0.171 \\
\hline hs-CRP, mg/L & $2.01 \pm 1.74$ & $3.38 \pm 3.93$ & $3.45 \pm 4.12$ & $6.31 \pm 10.00$ & 0.090 & 0.086 & 0.027 & 0.943 & 0.143 & 0.155 \\
\hline $\begin{array}{l}\text { Coronary } \\
\text { arteries }\end{array}$ & 42 & 43 & 42 & 40 & 0.158 & 0.520 & 0.790 & 0.714 & 0.207 & 0.616 \\
\hline LAD, $n(\%)$ & $16(38.1)$ & $22(51.2)$ & $20(47.6)$ & $18(45.0)$ & & & & & & \\
\hline LCX, $n$ (\%) & $8(19.0)$ & 11 (25.6) & $9(21.4)$ & $6(15.0)$ & & & & & & \\
\hline $\mathrm{RCA}, n(\%)$ & $18(42.9)$ & 10 (23.2) & 13 (31.0) & $16(40.0)$ & & & & & & \\
\hline
\end{tabular}

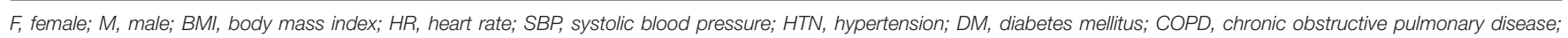

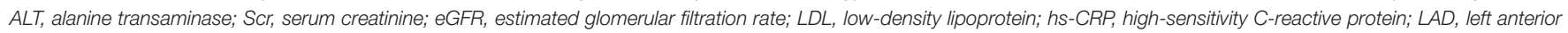
descending artery; LCX, left circumflex artery; RCA, right coronary artery.

than those with large calcification $(26.06 \pm 16.54$ vs. $17.55 \pm$ $7.65 \mathrm{ng} / \mathrm{mL}, P=0.002$ ) (Figure 3B).

\section{DISCUSSION}

The main findings of this study are as follows: (a) Among the four coronary plaque component phenotypes assessed by CCTA, the serum SST2 level was correlated with the NC and DC components. The volume of the NC component was larger in patients with higher serum sST2 levels, while that of the DC was decreased in these patients. (b) Further subgroup analysis revealed that patients with spotty calcification had higher serum sST2 levels than those with large calcification.

Previous studies have shown that inflammation plays an essential role in atherosclerosis, especially in NC formation, and NC has been proven to be tightly correlated with plaque vulnerability (23-29). As an important inflammatory factor, sST2 exerts proinflammatory effects and regulates the pathogenesis of atherosclerosis. A recent study by Zhang et al., as mentioned above, demonstrated that patients with ACS had higher serum sST2 levels than those with stable angina pectoris (SAP), which suggested that SST2 is potentially associated with plaque vulnerability (4). In our study, we further investigated the correlation between the serum sST2 level and plaque vulnerability by assessing the coronary plaque components in patients with non-ST-elevation ACS and revealed a positive correlation between the serum sST2 level and NC component in coronary lesions.

The role of calcification in plaque vulnerability remains controversial. Previous studies have reported a biphasic association between calcification and plaque vulnerability, as spotty calcification was more often found in ruptured plaques, while large calcification was more strongly related to stable plaques (30). Interestingly, patients with higher serum sST2 levels had smaller intraplaque calcification volumes in our study, and further subgroup analysis revealed that patients with spotty calcification had higher serum sST2 levels than those with large calcification. Furthermore, macrophages may play a role in the relationship between sST2 and calcification. Previous studies have demonstrated that SST2 may suppress the differentiation of macrophages toward the anti-inflammatory M2 phenotype (31). Proinflammatory M1 macrophages may facilitate microcalcification formation in plaque progression, leading to plaque rupture, while anti-inflammatory M2 macrophages are related to macrocalcification in plaque regression, suggesting plaque stability (32).

However, we did not observe associations between the serum sST2 level and plaque components at the level of the MLA. 
TABLE 2 | Serum sST2 level and plaque components in volumetric analysis of the whole lesion.

\begin{tabular}{|c|c|c|c|c|c|c|c|c|c|c|}
\hline & \multirow{2}{*}{$\begin{array}{c}\text { Quartile } 1 \\
\qquad(N=30) \\
<14.5 \mathrm{ng} / \mathrm{mL}\end{array}$} & \multirow{2}{*}{$\begin{array}{c}\text { Quartile } 2 \\
(N=30) \\
14.5-20.5 \\
\text { ng/mL }\end{array}$} & \multirow{2}{*}{$\begin{array}{c}\text { Quartile } 3 \\
(N=30) \\
20.5-25.9 \\
\text { ng/mL }\end{array}$} & \multirow{2}{*}{$\begin{array}{c}\text { Quartile } 4 \\
(N=30) \\
>25.9 \mathrm{ng} / \mathrm{mL}\end{array}$} & \multicolumn{6}{|c|}{$P$-value } \\
\hline & & & & & $\begin{array}{c}\text { Quartile } 2 \\
\text { vs. } \\
\text { Quartile } 1\end{array}$ & $\begin{array}{c}\text { Quartile } 3 \\
\text { vs. } \\
\text { Quartile 1 }\end{array}$ & $\begin{array}{c}\text { Quartile } 4 \\
\text { vs. } \\
\text { Quartile 1 }\end{array}$ & $\begin{array}{c}\text { Quartile } 3 \\
\text { vs. } \\
\text { Quartile } 2\end{array}$ & $\begin{array}{c}\text { Quartile } 4 \\
\text { vs. } \\
\text { Quartile } 2\end{array}$ & $\begin{array}{c}\text { Quartile 4 } \\
\text { vs. } \\
\text { Quartile 3 }\end{array}$ \\
\hline $\begin{array}{l}\text { Analyzed } \\
\text { lesions, } n\end{array}$ & 42 & 43 & 42 & 40 & & & & & & \\
\hline $\begin{array}{l}\text { Plaque volume, } \\
\mathrm{mm}^{3}\end{array}$ & $240.18 \pm 209.36$ & $217.95 \pm 133.49$ & $230.18 \pm 181.63$ & $220.45 \pm 143.18$ & 0.562 & 0.816 & 0.618 & 0.725 & 0.935 & 0.788 \\
\hline $\begin{array}{l}\text { Mean plaque } \\
\text { burden, \% }\end{array}$ & $60.34 \pm 8.78$ & $62.47 \pm 7.71$ & $60.86 \pm 12.64$ & $59.80 \pm 9.35$ & 0.238 & 0.829 & 0.787 & 0.480 & 0.160 & 0.666 \\
\hline $\begin{array}{l}\text { Maximal plaque } \\
\text { thickness, mm }\end{array}$ & $2.57 \pm 0.70$ & $2.45 \pm 0.74$ & $2.41 \pm 0.86$ & $2.36 \pm 0.50$ & 0.421 & 0.352 & 0.110 & 0.844 & 0.512 & 0.718 \\
\hline $\begin{array}{l}\text { Fibrous volume, } \\
\mathrm{mm}^{3}\end{array}$ & $73.79 \pm 40.17$ & $75.36 \pm 43.05$ & $74.62 \pm 57.81$ & $73.73 \pm 46.89$ & 0.862 & 0.939 & 0.995 & 0.947 & 0.870 & 0.939 \\
\hline $\begin{array}{l}\text { Fibrous volume, } \\
\%\end{array}$ & $35.32 \pm 13.42$ & $38.97 \pm 13.24$ & $37.50 \pm 16.72$ & $34.80 \pm 9.91$ & 0.211 & 0.512 & 0.841 & 0.656 & 0.107 & 0.374 \\
\hline $\begin{array}{l}\text { Fibrous fatty } \\
\text { volume, } \mathrm{mm}^{3}\end{array}$ & $35.80 \pm 19.47$ & $35.49 \pm 23.50$ & $36.87 \pm 30.42$ & $37.34 \pm 28.21$ & 0.947 & 0.848 & 0.775 & 0.816 & 0.747 & 0.942 \\
\hline $\begin{array}{l}\text { Fibrous fatty } \\
\text { volume, } \%\end{array}$ & $18.25 \pm 7.10$ & $17.95 \pm 7.15$ & $18.18 \pm 7.19$ & $18.13 \pm 7.26$ & 0.848 & 0.964 & 0.937 & 0.885 & 0.914 & 0.973 \\
\hline $\begin{array}{l}\text { Necrotic core } \\
\text { volume, } \mathrm{mm}^{3}\end{array}$ & $45.10 \pm 45.80$ & $50.22 \pm 42.56$ & $62.65 \pm 69.86$ & $86.16 \pm 59.71$ & 0.595 & 0.178 & 0.001 & 0.326 & 0.002 & 0.105 \\
\hline $\begin{array}{l}\text { Necrotic core } \\
\text { volume, \% }\end{array}$ & $23.21 \pm 16.18$ & $22.50 \pm 14.03$ & $25.04 \pm 14.48$ & $35.16 \pm 9.82$ & 0.829 & 0.588 & $<0.001$ & 0.415 & $<0.001$ & $<0.001$ \\
\hline $\begin{array}{l}\text { Dense calcium } \\
\text { volume, } \mathrm{mm}^{3}\end{array}$ & $74.21 \pm 172.44$ & $48.16 \pm 78.62$ & $39.11 \pm 67.42$ & $16.72 \pm 26.96$ & 0.376 & 0.225 & 0.039 & 0.570 & 0.017 & 0.051 \\
\hline $\begin{array}{l}\text { Dense calcium } \\
\text { volume, } \%\end{array}$ & $18.07 \pm 22.13$ & $17.66 \pm 19.89$ & $14.61 \pm 18.40$ & $7.23 \pm 9.76$ & 0.929 & 0.438 & 0.005 & 0.464 & 0.003 & 0.026 \\
\hline
\end{tabular}

TABLE 3 | Correlation between serum sST2 and plaque components in volumetric analysis of the whole lesion.

\begin{tabular}{lcc}
\hline Parameters & Pearson correlation & $P$-value \\
\hline Plaque volume, $\mathrm{mm}^{3}$ & -0.019 & 0.807 \\
Mean plaque burden, \% & 0.018 & 0.818 \\
Maximal plaque thickness, mm & -0.071 & 0.363 \\
Fibrous volume, $\mathrm{mm}^{3}$ & -0.059 & 0.446 \\
Fibrous volume, \% & -0.166 & 0.056 \\
Fibrous fatty volume, $\mathrm{mm}^{3}$ & 0.088 & 0.257 \\
Fibrous fatty volume, \% & 0.093 & 0.230 \\
Necrotic core volume, $\mathrm{mm}^{3}$ & 0.323 & $<0.001$ \\
Necrotic core volume, \% & 0.425 & $<0.001$ \\
Dense calcium volume, $\mathrm{mm}^{3}$ & -0.208 & 0.007 \\
Dense calcium volume, \% & -0.275 & $<0.001$ \\
\hline
\end{tabular}

Perhaps the cross-sectional characteristics of the plaques at the level of the MLA were unable to reflect the characteristics of the whole plaque. Moreover, a similar conclusion was drawn in a previous study focused on carotid plaques, as no associations between serum sST2 levels and cross-sectional plaque characteristics were found on specimens from carotid endarterectomy (33).
In addition, we have observed that higher serum sST2 levels were correlated with older age in our study, which is consistent with previous studies $(4,34)$. Usually, aging is accompanied with alterations of cytokine expression toward a pro-inflammatory pattern (35-37). sST2, a modulator of the inflammatory response, might increase with age and exert a pro-inflammatory effect, while the underlying mechanisms need further study.

The current study does have some limitations. First, the study was observational in nature and was performed at a single center. Second, although this preliminary study has observed associations between serum sST2 levels and plaque vulnerability, only surrogate and not clinical endpoints were analyzed due to a relatively small sample size. Previous studies have demonstrated that elevation of serum sST2 levels were associated with poor prognosis in patients with myocardial infarction (MI) and heart failure (HF) (6-8). A larger sample size study is required in future to further investigate the predictive value of serum sST2 on long-term prognosis of patients with non-ST-elevation ACS. Third, although our study revealed that serum sST2 levels were correlated with $\mathrm{NC}$ and DC plaque components, the underlying mechanisms remain unclear. Previous study reported the role of sST2 in facilitating M1 macrophage polarization, which participated in the formation of spotty calcification and vulnerable plaque $(31,32,38)$. However, the pathophysiological effects of sST2 on plaque vulnerability remain largely unknown, which need further mechanistic studies. 
TABLE 4 | Serum sST2 and plaque components at the level of the MLA.

\begin{tabular}{|c|c|c|c|c|c|c|c|c|c|c|}
\hline & \multirow{2}{*}{$\begin{array}{c}\text { Quartile 1 } \\
\qquad(N=30) \\
<14.5 \mathrm{ng} / \mathrm{mL}\end{array}$} & \multirow{2}{*}{$\begin{array}{c}\text { Quartile } 2 \\
\text { (N=30) } \\
14.5-20.5 \\
\mathrm{ng} / \mathrm{mL}\end{array}$} & \multirow{2}{*}{$\begin{array}{c}\text { Quartile } 3 \\
(N=30) \\
20.5-25.9 \\
\mathrm{ng} / \mathrm{mL}\end{array}$} & \multirow{2}{*}{$\begin{array}{c}\text { Quartile } 4 \\
(N=30) \\
>25.9 \mathrm{ng} / \mathrm{mL}\end{array}$} & \multicolumn{6}{|c|}{$P$-value } \\
\hline & & & & & $\begin{array}{c}\text { Quartile } 2 \\
\text { vs. } \\
\text { Quartile } 1\end{array}$ & $\begin{array}{c}\text { Quartile } 3 \\
\text { vs. } \\
\text { Quartile } 1\end{array}$ & $\begin{array}{c}\text { Quartile } 4 \\
\text { vs. } \\
\text { Quartile 1 }\end{array}$ & $\begin{array}{c}\text { Quartile } 3 \\
\text { vs. } \\
\text { Quartile } 2\end{array}$ & $\begin{array}{c}\text { Quartile } 4 \\
\text { vs. } \\
\text { Quartile } 2\end{array}$ & $\begin{array}{c}\text { Quartile } 4 \\
\text { vs. } \\
\text { Quartile 3 }\end{array}$ \\
\hline $\begin{array}{l}\text { Analyzed } \\
\text { lesions, } n\end{array}$ & 42 & 43 & 42 & 40 & & & & & & \\
\hline $\begin{array}{l}\text { Eccentricity } \\
\text { index }\end{array}$ & $0.65 \pm 015$ & $0.68 \pm 0.22$ & $0.71 \pm 0.21$ & $0.72 \pm 0.26$ & 0.602 & 0.174 & 0.182 & 0.453 & 0.420 & 0.897 \\
\hline $\begin{array}{l}\text { Plaque burden, } \\
\%\end{array}$ & $79.11 \pm 12.21$ & $81.43 \pm 10.49$ & $77.31 \pm 14.23$ & $76.93 \pm 15.13$ & 0.378 & 0.561 & 0.497 & 0.150 & 0.132 & 0.911 \\
\hline $\begin{array}{l}\text { Remodeling } \\
\text { index }\end{array}$ & $1.01 \pm 0.16$ & $0.98 \pm 0.11$ & $0.97 \pm 0.15$ & $0.97 \pm 0.19$ & 0.285 & 0.166 & 0.392 & 0.966 & 0.983 & 0.989 \\
\hline $\begin{array}{l}\text { Maximal plaque } \\
\text { thickness, mm }\end{array}$ & $1.96 \pm 0.47$ & $1.91 \pm 0.49$ & $2.08 \pm 0.56$ & $1.86 \pm 0.63$ & 0.627 & 0.320 & 0.428 & 0.148 & 0.702 & 0.107 \\
\hline $\begin{array}{l}\text { Fibrous area, } \\
\mathrm{mm}^{2}\end{array}$ & $3.24 \pm 2.27$ & $3.18 \pm 1.89$ & $2.94 \pm 1.84$ & $2.64 \pm 1.88$ & 0.899 & 0.538 & 0.222 & 0.574 & 0.209 & 0.483 \\
\hline Fibrous area, \% & $27.11 \pm 16.02$ & $26.26 \pm 12.41$ & $24.20 \pm 14.14$ & $27.45 \pm 18.65$ & 0.796 & 0.411 & 0.934 & 0.495 & 0.741 & 0.395 \\
\hline $\begin{array}{l}\text { Fibrous fatty } \\
\text { area, } \mathrm{mm}^{2}\end{array}$ & $2.86 \pm 2.35$ & $2.29 \pm 1.29$ & $2.37 \pm 1.97$ & $2.14 \pm 1.41$ & 0.203 & 0.340 & 0.119 & 0.831 & 0.625 & 0.560 \\
\hline $\begin{array}{l}\text { Fibrous fatty } \\
\text { area, \% }\end{array}$ & $21.92 \pm 12.91$ & $21.06 \pm 11.88$ & $18.24 \pm 11.26$ & $19.20 \pm 10.32$ & 0.764 & 0.197 & 0.322 & 0.282 & 0.458 & 0.699 \\
\hline $\begin{array}{l}\text { Necrotic core } \\
\text { area, } \mathrm{mm}^{2}\end{array}$ & $4.12 \pm 2.28$ & $4.00 \pm 3.01$ & $4.20 \pm 3.21$ & $3.33 \pm 3.01$ & 0.850 & 0.895 & 0.205 & 0.777 & 0.321 & 0.223 \\
\hline $\begin{array}{l}\text { Necrotic core } \\
\text { area, \% }\end{array}$ & $32.00 \pm 15.17$ & $33.24 \pm 19.02$ & $31.62 \pm 20.14$ & $28.99 \pm 21.61$ & 0.751 & 0.927 & 0.488 & 0.714 & 0.357 & 0.585 \\
\hline $\begin{array}{l}\text { Dense calcium } \\
\text { area, } \mathrm{mm}^{2}\end{array}$ & $1.11 \pm 2.02$ & $1.77 \pm 2.77$ & $2.00 \pm 3.08$ & $1.93 \pm 2.92$ & 0.232 & 0.146 & 0.165 & 0.732 & 0.809 & 0.917 \\
\hline $\begin{array}{l}\text { Dense calcium } \\
\text { area, \% }\end{array}$ & $9.69 \pm 15.78$ & $14.24 \pm 20.60$ & $15.59 \pm 23.80$ & $17.15 \pm 23.69$ & 0.279 & 0.213 & 0.116 & 0.789 & 0.564 & 0.776 \\
\hline
\end{tabular}
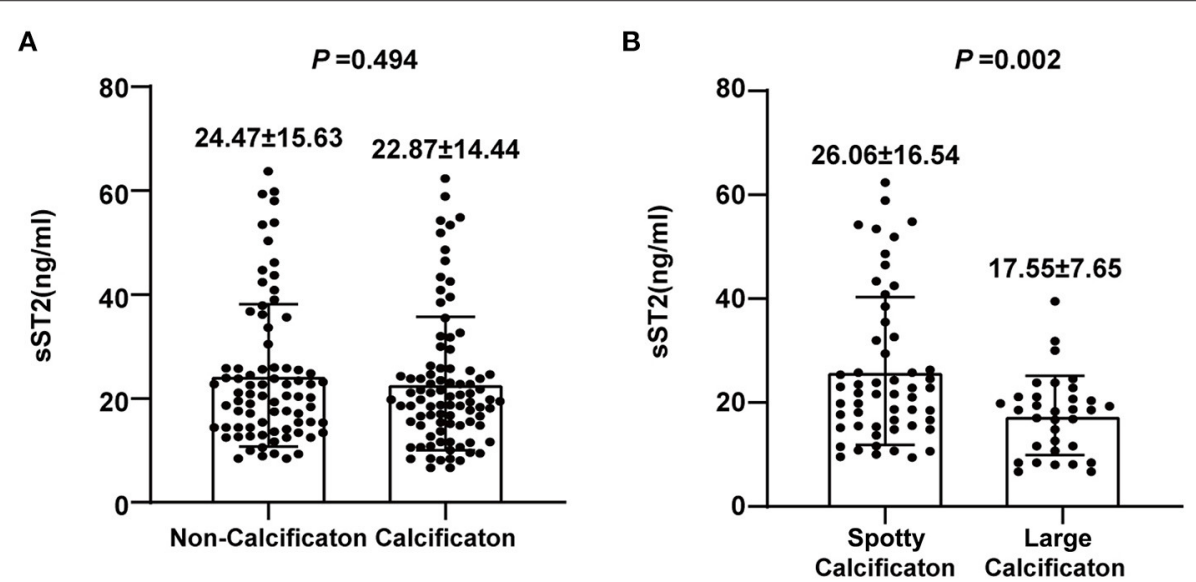

FIGURE 3 | Analysis of the association between sST2 and plaque calcification. (A) No significant difference in serum sST2 levels was observed between the calcification and non-calcification groups. (B) Patients with spotty calcification had higher sST2 levels than those with large calcification.

\section{CONCLUSIONS}

Our study demonstrated that serum sST2 levels were correlated with different coronary plaque components in patients with non-ST-elevation ACS. Patients with higher serum sST2 levels had a larger NC plaque component. The serum sST2 level might be a useful predictive marker of plaque vulnerability in patients with non-ST-elevation ACS.

\section{DATA AVAILABILITY STATEMENT}

The original contributions presented in the study are included in the article/supplementary 
material, further inquiries can be directed to the corresponding author/s.

\section{ETHICS STATEMENT}

The studies involving human participants were reviewed and approved by Institutional Review Board of Renji Hospital. The patients/participants provided their written informed consent to participate in this study.

\section{AUTHOR CONTRIBUTIONS}

SD and JP conceived and designed the study and amended the manuscript. GL, YQ, ZW, and FL acquired clinical data. QF and YY analyzed QAngioCT data. XS and JS executed the statistical analysis. GL and YQ drafted the manuscript. All authors contributed to the interpretation of the data and approved the final version of this manuscript.

\section{REFERENCES}

1. Boogers MJ, Schuijf JD, Kitslaar PH, van Werkhoven JM, de Graaf FR, Boersma E, et al. Automated quantification of stenosis severity on 64-slice CT: a comparison with quantitative coronary angiography. JACC Cardiovasc Imaging. (2010) 3:699-709. doi: 10.1016/j.jcmg.2010.01.010

2. Boogers MJ, Broersen A, van Velzen JE, de Graaf FR, El-Naggar HM, Kitslaar $\mathrm{PH}$, et al. Automated quantification of coronary plaque with computed tomography: comparison with intravascular ultrasound using a dedicated registration algorithm for fusion-based quantification. Eur Heart J. (2012) 33:1007-16. doi: 10.1093/eurheartj/ehr465

3. Papadopoulou SL, Neefjes LA, Garcia-Garcia HM, Flu WJ, Rossi A, Dharampal AS, et al. Natural history of coronary atherosclerosis by multislice computed tomography. JACC Cardiovasc Imaging. (2012) 5(3 Suppl):S2837. doi: 10.1016/j.jcmg.2012.01.009

4. Zhang Y, Fan Z, Liu H, Ma J, Zhang M. Correlation of plasma soluble suppression of tumorigenicity-2 level with the severity and stability of coronary atherosclerosis. Coron Artery Dis. (2020) 31:62835. doi: 10.1097/MCA.0000000000000851

5. Aimo A, Migliorini P, Vergaro G, Franzini M, Passino C, Maisel A, et al. The IL-33/ST2 pathway, inflammation and atherosclerosis: trigger and target? Int J Cardiol. (2018) 267:188-92. doi: 10.1016/j.ijcard.2018.05.056

6. Aimo A, Vergaro G, Passino C, Ripoli A, Ky B, Miller WL, et al. Prognostic value of soluble suppression of tumorigenicity-2 in chronic heart failure: a meta-analysis. JACC Heart Fail. (2017) 5:280-6. doi: 10.1016/j.jchf.2016.09.010

7. Aimo A, Vergaro G, Ripoli A, Bayes-Genis A, Pascual Figal DA, de Boer RA, et al. Meta-Analysis of soluble suppression of tumorigenicity2 and prognosis in acute heart failure. JACC Heart Fail. (2017) 5:28796. doi: 10.1016/j.jchf.2016.12.016

8. Jenkins WS, Roger VL, Jaffe AS, Weston SA, AbouEzzeddine OF, Jiang R, et al. Prognostic value of soluble ST2 after myocardial infarction: a community perspective. Am J Med. (2017) 130:1112.e9.e15. doi: 10.1016/j.amjmed.2017.02.034

9. Miller AM, Xu D, Asquith DL, Denby L, Li Y, Sattar N, et al. IL-33 reduces the development of atherosclerosis. J Exp Med. (2008) 205:33946. doi: 10.1084/jem.20071868

10. Roffi M, Patrono C, Collet JP, Mueller C, Valgimigli M, Andreotti F, et al. 2015 ESC guidelines for the management of acute coronary syndromes in patients presenting without persistent ST-segment elevation: task force for the management of acute coronary syndromes in patients presenting without persistent ST-Segment Elevation of the European Society of Cardiology (ESC). Eur Heart J. (2016) 37:267-315. doi: 10.1093/eurheartj/ehv320

\section{FUNDING}

This work was supported by grants from the National Key R\&D Program of China (2018YFC1312802), National Natural Science Foundation of China (82070477 and 81800223), Shanghai ShenKang Hospital Development Center (SHDC12019X12), Shanghai Jiao Tong University School of Medicine Multi-center clinical research project DLY201804, and Shanghai Sailing Program (18YF1413500).

\section{ACKNOWLEDGMENTS}

The authors would like to acknowledge the core laboratory (CardHemo, Med-X Research Institute, Shanghai Jiao Tong University, Shanghai, China) for guidance and quality control of QAngioCT analysis.

11. Fuchs S, Lavi I, Tzang O, Fuchs S, Brosh D, Bental T, et al. Necrotic core and thin cap fibrous atheroma distribution in native coronary artery lesion-containing segments: a virtual histology intravascular ultrasound study. Coron Artery Dis. (2011) 22:339-44. doi: 10.1097/MCA.0b013e32834 67829

12. Ito T, Terashima M, Kaneda $\mathrm{H}$, Nasu K, Matsuo H, Ehara M, et al. Comparison of in vivo assessment of vulnerable plaque by 64-slice multislice computed tomography versus optical coherence tomography. Am J Cardiol. (2011) 107:1270-7. doi: 10.1016/j.amjcard.2010.12.036

13. Deftereos S, Giannopoulos G, Kossyvakis C, Kaoukis A, Raisakis K, Panagopoulou V, et al. Association of soluble tumour necrosis factorrelated apoptosis-inducing ligand levels with coronary plaque burden and composition. Heart. (2012) 98:214-8. doi: 10.1136/heartjnl-2011-300339

14. de Graaf MA, Broersen A, Kitslaar PH, Roos CJ, Dijkstra J, Lelieveldt BP, et al. Automatic quantification and characterization of coronary atherosclerosis with computed tomography coronary angiography: cross-correlation with intravascular ultrasound virtual histology. Int J Cardiovasc Imaging. (2013) 29:1177-90. doi: 10.1007/s10554-013-0194-x

15. Brodoefel H, Reimann A, Heuschmid M, Tsiflikas I, Kopp AF, Schroeder S, et al. Characterization of coronary atherosclerosis by dual-source computed tomography and HU-based color mapping: a pilot study. Eur Radiol. (2008) 18:2466-74. doi: 10.1007/s00330-008-1019-5

16. Motoyama S, Sarai M, Harigaya H, Anno $H$, Inoue $K$, Hara $T$, et al. Computed tomographic angiography characteristics of atherosclerotic plaques subsequently resulting in acute coronary syndrome. J Am Coll Cardiol. (2009) 54:49-57. doi: 10.1016/j.jacc.2009.02.068

17. Precht H, Kitslaar PH, Broersen A, Dijkstra J, Gerke O, Thygesen J, et al. Influence of adaptive statistical iterative reconstruction on coronary plaque analysis in coronary computed tomography angiography. J Cardiovasc Comput Tomogr. (2016) 10:507-16. doi: 10.1016/j.jcct.2016.09.006

18. Mintz GS, Nissen SE, Anderson WD, Bailey SR, Erbel R, Fitzgerald PJ, et al. American college of cardiology clinical expert consensus document on standards for acquisition, measurement and reporting of Intravascular Ultrasound Studies (IVUS). a report of the american college of cardiology task force on clinical expert consensus documents. J Am Coll Cardiol. (2001) 37:1478-92. doi: 10.1016/s0735-1097(01)01175-5

19. Higuma T, Soeda T, Abe N, Yamada M, Yokoyama H, Shibutani S, et al. A combined optical coherence tomography and intravascular ultrasound study on plaque rupture, plaque erosion, and calcified nodule in patients with st-segment elevation myocardial infarction: incidence, morphologic characteristics, and outcomes after percutaneous coronary intervention. JACC Cardiovasc Interv. (2015) 8:1166-76. doi: 10.1016/j.jcin.2015. 02.026 
20. Kröner ES, van Velzen JE, Boogers MJ, Siebelink HM, Schalij MJ, Kroft LJ, et al. Positive remodeling on coronary computed tomography as a marker for plaque vulnerability on virtual histology intravascular ultrasound. Am J Cardiol. (2011) 107:1725-9. doi: 10.1016/j.amjcard.2011.02.337

21. Ehara S, Kobayashi Y, Yoshiyama M, Shimada K, Shimada Y, Fukuda D, et al. Spotty calcification typifies the culprit plaque in patients with acute myocardial infarction: an intravascular ultrasound study. Circulation. (2004) 110:3424-9. doi: 10.1161/01.CIR.0000148131.41425.E9

22. Motoyama S, Kondo T, Sarai M, Sugiura A, Harigaya H, Sato T, et al. Multislice computed tomographic characteristics of coronary lesions in acute coronary syndromes. J Am Coll Cardiol. (2007) 50:319-26. doi: 10.1016/j.jacc.2007.03.044

23. Wolf D, Ley K. Immunity and inflammation in atherosclerosis. Circ Res. (2019) 124:315-27. doi: 10.1161/CIRCRESAHA.118.313591

24. Grootaert MOJ, Schrijvers DM, Van Spaendonk H, Breynaert A, Hermans $\mathrm{N}$, Van Hoof VO, et al. NecroX-7 reduces necrotic core formation in atherosclerotic plaques of Apoe knockout mice. Atherosclerosis. (2016) 252:166-74. doi: 10.1016/j.atherosclerosis.2016.06.045

25. Otsuka F, Yasuda S, Noguchi T, Ishibashi-Ueda H. Pathology of coronary atherosclerosis and thrombosis. Cardiovasc Diagn Ther. (2016) 6:396408. doi: 10.21037/cdt.2016.06.01

26. Nasu K, Tsuchikane E, Katoh O, Vince DG, Virmani R, Surmely JF, et al. Accuracy of in vivo coronary plaque morphology assessment: a validation study of in vivo virtual histology compared with in vitro histopathology. J Am Coll Cardiol. (2006) 47:2405-12. doi: 10.1016/j.jacc.2006. 02.044

27. $\mathrm{Pu}$ J, Mintz GS, Brilakis ES, Banerjee S, Abdel-Karim AR, Maini B, et al. In vivo characterization of coronary plaques: novel findings from comparing greyscale and virtual histology intravascular ultrasound and nearinfrared spectroscopy. Eur Heart J. (2012) 33:372-83. doi: 10.1093/eurheartj/ ehr387

28. Pu J, Mintz GS, Biro S, Lee JB, Sum ST, Madden SP, et al. Insights into echo-attenuated plaques, echolucent plaques, and plaques with spotty calcification: novel findings from comparisons among intravascular ultrasound, near-infrared spectroscopy, and pathological histology in 2,294 human coronary artery segments. J Am Coll Cardiol. (2014) 63:222033. doi: $10.1016 /$ j.jacc.2014.02.576

29. Ding S, Xu L, Yang F, Kong L, Zhao Y, Gao L, et al. Association between tissue characteristics of coronary plaque and distal embolization after coronary intervention in acute coronary syndrome patients: insights from a metaanalysis of virtual histology-intravascular ultrasound studies. PLOS ONE. (2014) 9:e106583. doi: 10.1371/journal.pone.0106583
30. Shi X, Gao J, Lv Q, Cai H, Wang F, Ye R, et al. Calcification in atherosclerotic plaque vulnerability: friend or foe? Front Physiol. (2020) 11:56. doi: 10.3389/fphys.2020.00056

31. Ono Y, Yoshino O, Hiraoka T, Akiyama I, Sato E, Ito M, et al. IL-33 exacerbates endometriotic lesions via polarizing peritoneal macrophages to M2 subtype. Reprod Sci. (2020) 27:869-76. doi: 10.1007/s43032-019-00090-9

32. Shioi A, Ikari Y. Plaque calcification during atherosclerosis progression and regression. J Atheroscler Thromb. (2018) 25:294-303. doi: 10.5551/jat.RV17020

33. Willems S, Quax PH, de Borst GJ, de Vries JP, Moll FL, de Kleijn DP, et al. Soluble ST2 levels are not associated with secondary cardiovascular events and vulnerable plaque phenotype in patients with carotid artery stenosis. Atherosclerosis. (2013) 231:48-53. doi: 10.1016/j.atherosclerosis.2013.08.024

34. Kohli P, Bonaca MP, Kakkar R, Kudinova AY, Scirica BM, Sabatine MS, et al. Role of ST2 in non-ST-elevation acute coronary syndrome in the MERLIN-TIMI 36 trial. Clin Chem. (2012) 58:257-66. doi: 10.1373/clinchem.2011.173369

35. Xia S, Zhang X, Zheng S, Khanabdali R, Kalionis B, Wu J, et al. An update on inflamm-aging: mechanisms, prevention, and treatment. J Immunol Res. (2016) 2016:8426874. doi: 10.1155/2016/8426874

36. Rea IM, Gibson DS, McGilligan V, McNerlan SE, Alexander HD, Ross OA. Age and age-related diseases: role of inflammation triggers and cytokines. Front Immunol. (2018) 9:586. doi: 10.3389/fimmu.2018.00586

37. Huang Y, Hu C, Ye H, Luo R, Fu X, Li X, et al. Inflamm-aging: a new mechanism affecting premature ovarian insufficiency. J Immunol Res. (2019) 2019:8069898. doi: 10.1155/2019/8069898

38. Ding S, Lin N, Sheng X, Zhao Y, Su Y, Xu L, et al. Melatonin stabilizes rupture-prone vulnerable plaques via regulating macrophage polarization in a nuclear circadian receptor ROR $\alpha$-dependent manner. J Pineal Res. (2019) 67:e12581. doi: 10.1111/jpi.12581

Conflict of Interest: The authors declare that the research was conducted in the absence of any commercial or financial relationships that could be construed as a potential conflict of interest.

Copyright (C) 2021 Luo, Qian, Sheng, Sun, Wu, Liao, Feng, Yin, Ding and Pu. This is an open-access article distributed under the terms of the Creative Commons Attribution License (CC BY). The use, distribution or reproduction in other forums is permitted, provided the original author(s) and the copyright owner(s) are credited and that the original publication in this journal is cited, in accordance with accepted academic practice. No use, distribution or reproduction is permitted which does not comply with these terms. 